\title{
Reproducibility of histamine challenge tests in asthmatic children
}

\author{
D HARIPARSAD, N WILSON, C DIXON, M SILVERMAN \\ From the Department of Paediatrics and Neonatal Medicine, and Department of Medicine, Royal \\ Postgraduate Medical School, Hammersmith Hospital, London
}

ABSTRACT The measurement of bronchial reactivity by histamine challenge testing is of increasing clinical importance in paediatrics. By means of a simple tidal breathing technique for the measurement of histamine sensitivity (expressed as $\mathrm{PC}_{20}$-the concentration of histamine which ${ }^{\infty}$ produces a $20 \%$ fall in peak flow rate) in childhood asthma, the reproducibility of pairs of tests 9 was estimated over one hour and 24-hour intervals in 22 children. Under carefully controlled conditions the $95 \%$ confidence limits of $\mathrm{PC}_{20}$ were $0 \cdot 8-1.25 \times$ baseline $\mathrm{PC}_{20}$ after one hour and $0 \cdot 36-2 \cdot 8 \times$ baseline $\mathrm{PC}_{20}$ after 24 hours.

Increased bronchial sensitivity to a wide variety of inhaled substances is a characteristic feature of asthma..$^{1-4}$ Histamine solution, inhaled as an aerosol, may act on irritant receptors inducing bronchospasm via vagal reflexes ${ }^{5}$ or may act directly on bronchial smooth muscle. ${ }^{6}$ Whatever the mechanism, the use of histamine inhalation tests to measure bronchial reactivity has gained acceptance and their use in clinical practice, epidemiology, and research in asthma is becoming increasingly important.

In adult asthmatic patients histamine challenge tests carried out at intervals varying from 30 minutes to one week are highly reproducible,,$^{7-9}$ although some patients may develop tolerance to multiple histamine challenges.8 ${ }^{811}{ }^{11}$ Recently we devised a technique for studying the effect of various food substances on bronchial reactivity in asthmatic children, using multiple histamine challenges. ${ }^{12}$ The significance of any change in bronchial reactivity brought about by exposure to a suspect food substance (or any other potential asthma-provoking agent) can be determined only with a knowledge of the reproducibility of the histamine challenge test. In this paper we report the reproducibility of the histamine challenge test in children.

\section{Methods}

The study group consisted of 22 asthmatic children,

Address for reprint requests: Dr M Silverman, Department of Paediatrics and Neonatal Medicine, Hammersmith Hospital, London W12 0HS

Accepted 7 January 1983
18 of whom were boys. Their mean age was 11 years (range 6-17 years). Asthmatic symptoms were well controlled with medication in all patients, as judged by the history and by the fact that the mean baseline peak expiratory flow rate (PEFR) was $93 \%$ of the predicted value. ${ }^{13}$ Patients with a recent history of upper respiratory tract infection or vaccination were excluded from the study. The children attended the laboratory on two consecutive days at the same time of day. Beta-agonists and sodium cromoglycate were discontinued for at least eight hours and sustained-release aminophylline for 24 hours before each study period. None of the patients was taking antihistamines or oral corticosteroids.

After the baseline PEFR had been recorded with a Wright peak flow meter (Airmed), the maximum value from three attempts being accepted, a his- 0 tamine challenge test was performed according to the method described by Cockcroft et al. ${ }^{3}$ After a two-minute inhalation of a control solution of $0.9 \%$ phosphate buffered saline, increasing concentrations $\sigma$ of buffered histamine solution were inhaled by tidal $N$ breathing for two minutes each, at five-minute N intervals, from a Wright's nebuliser and mouthpiece. The PEFR was measured 30, 90, and 180 seconds after the end of each inhalation. The procedure con- $\frac{\mathscr{C}}{\Phi}$ tinued with doubling concentrations of histamine $\stackrel{\infty}{=}$ (from $0.63 \mathrm{mg} / \mathrm{ml}$ to a maximum concentration of 16 $\mathrm{mg} / \mathrm{ml}$ ) until at least a $20 \%$ fall in PEFR from a control value was recorded. A dose-response curve $\mathbb{D}$ was constructed and the dose which caused a $20 \%$ त fall in PEFR $\left(\mathrm{PC}_{20}\right)$ was calculated by interpolation. Thereafter PEFR was measured serially for the next 60 minutes, by which time baseline values were 
reached. Histamine challenge tests were repeated, in exactly the same way as the first, after intervals of one and 24 hours. Throughout the study each patient used the same nebuliser.

Statistical analysis was performed after logarithmic transformation of individual $\mathrm{PC}_{20}$ values. Paired $t$ tests were used to determine the significance of differences between pairs of values of $\mathrm{PC}_{20}$.

\section{Results}

Mean values of PEFR were similar before each pair of tests. Only two patients had PEFR values of less than $80 \%$ of the predicted value. For each test interval (one hour and 24 hours), baseline PEFR had changed by over $20 \%$ in only two of the 22 patients. For the group of children no correlation was found between baseline PEFR (expressed as a proportion of the predicted value) and the $\mathrm{PC}_{20}$.

There was no significant difference in mean $\mathrm{PC}_{20}$ values for the tests carried out after intervals of one and 24 hours. The $\mathrm{PC}_{20}$ values were highly reproducible, with a correlation coefficient of 0.99 at one hour (fig 1) and $0 \cdot 81$ at 24 hours (fig 2). The mean difference of the $\log \mathrm{PC}_{20}$ from the initial value was $0.114( \pm 0.047) \mathrm{mg} / \mathrm{ml}$ at one hour and 0.053 $( \pm 0.22) \mathrm{mg} / \mathrm{ml}$ at 24 hours. The $95 \%$ confidence limits for $\mathrm{PC}_{20}$ are $0.8-1.25 \times$ baseline $\mathrm{PC}_{20}$ after one hour and $0 \cdot 36-2.8 \times$ baseline $\mathrm{PC}_{20}$ after 24 hours.

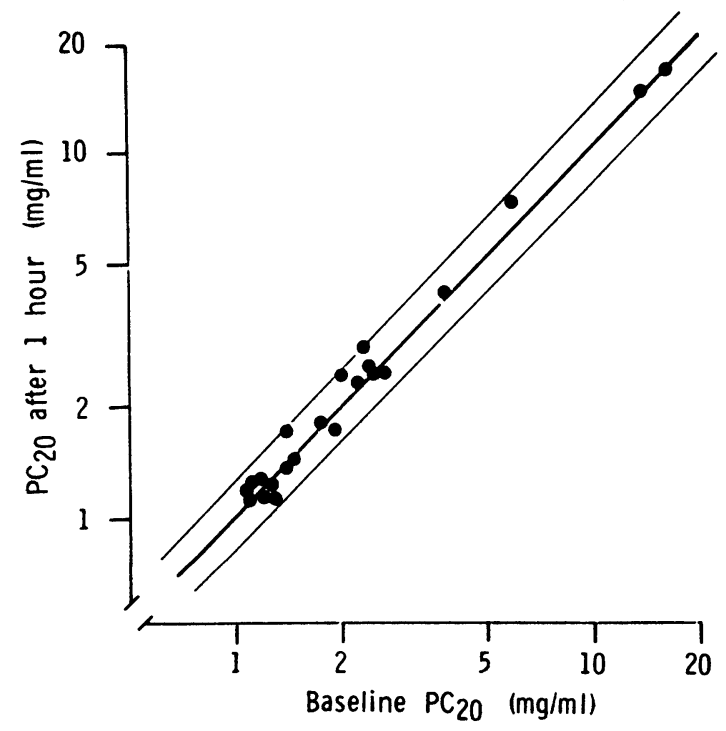

Fig 1 Reproducibility of histamine $P C_{20}$ after a one-hour interval. Individual data points are shown, with the line of identity and $95 \%$ confidence limits.

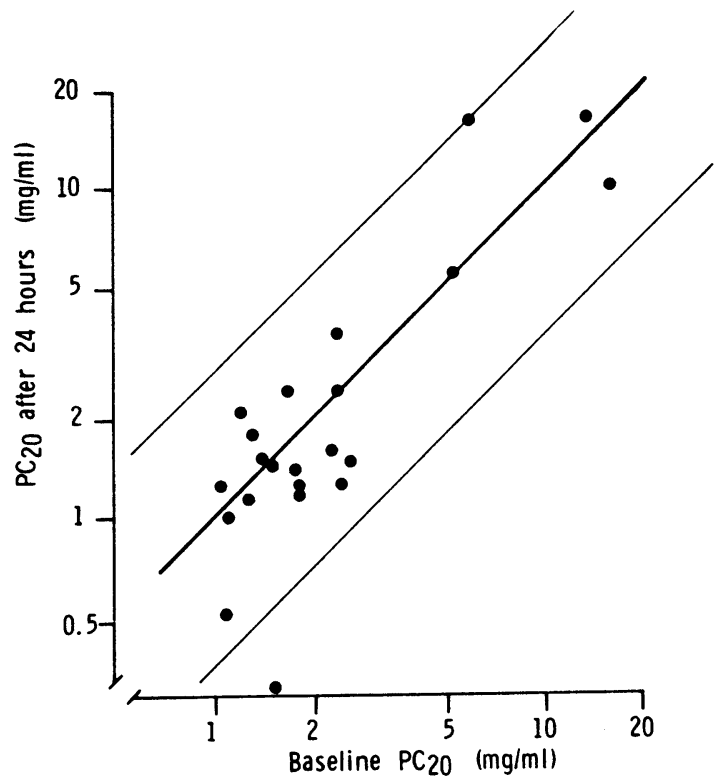

Fig 2 Reproducibility of histamine $P C_{20}$ after a 24-hour interval (symbols as in fig 1).

\section{Discussion}

This study has shown that histamine inhalation tests repeated after intervals of one and 24 hours are very reproducible in asthmatic children. These results confirm the work of others on adult asthma ${ }^{8} 9$ Ruffin et al, 9 using a method similar to ours, found that $\mathrm{PC}_{20}$ was highly reproducible at intervals ranging from 30 to 120 minutes and after up to four histamine challenges a day, although Schoeffel et al ${ }^{8}$ had suggested that a few individuals might develop tolerance to challenge tests repeated at 40 -minute intervals.

We have shown a higher degree of reproducibility after an interval of one hour $(r=0.997)$ than after 24 hours $(r=0 \cdot 81)$. Factors that may alter bronchial histamine sensitivity include inconsistent generation of aerosol by different nebulisers, alterations in the method of inhalation (that is, tidal breathing versus vital capacity breathing), testing at different times of the day, variations in initial airflow obstruction, respiratory infection, vaccination, allergen exposure, smoking, and medication. ${ }^{7}$ We controlled all these variables, although medication was easier to control at one hour than at 24 hours and this could be a possible explanation for the larger differences in $\mathrm{PC}_{20}$ noted in three of our patients after a 24-hour interval.

Multiple histamine challenge studies on individuals would allow the estimation of confidence limits, which would in turn permit a more sensitive assess- 
ment of individual patients. ${ }^{9}$ This is probably better than using the arbitrary two-fold change as the criterion for a significant alteration in $\mathrm{PC}_{20}$. Another useful application of multiple histamine challenge tests would be in studying the effect of multiple doses of a drug or allergen on bronchial reactivity over relatively short periods of time. From these studies a dose-response curve could be constructed to show the effect of the drug or allergen. Similarly, from a series of histamine challenges the time sequence of the effect of a drug or allergen on bronchial reactivity could be worked out.

When the variables which affect histamine sensitivity are controlled, the $\mathrm{PC}_{20}$ test is sufficiently simple and reproducible in children to be of clinical value in detecting altered bronchial reactivity after exposure to test agents. ${ }^{12}$

This work is part of a project supported by the Asthma Research Council.

\section{References}

' Herxheimer H. Bronchial obstruction induced by allergens, histamine and acetyl beta-methyl choline chloride. Int Arch Allergy 1951;19:9-13.

${ }^{2}$ Makino S. Clinical significance of bronchial sensitivity to acetyl choline and histamine in bronchial asthma. $J$ Allergy Clin Immunol 1966;38:127-42.
${ }^{3}$ Cockcroft DW, Killian DN, Mellon JJA, Hargreave FE. Bronchial reactivity to inhaled histamine: a method and clinical survey. Clin Allergy 1977;7:235-43.

${ }^{4}$ Laitinen LA. Histamine and metacholine challenge in the testing of bronchial reactivity. Scand $J$ Respir Dis 1974;suppl 86.

${ }^{5}$ Sellick H, Widdicombe JG. Stimulation of lung irritant receptors by cigarette smoke, carbon dust and histamine aerosol. J Appl Physiol 1971;31:15-9.

' Loring SH, Drazen JM, Ingram RH. Canine pulmonary response to aerosol histamine: direct versus vagal effects. J Appl Physiol 1977;42:946-52.

7 Juniper EF, Frith PA, Dunnett C, Cockcroft DW. Reproducibility and comparison of responses to inhaled histamine and methacholine. Thorax 1978;33:705-10.

${ }^{8}$ Schoeffel RE, Anderson SD, Gillam I, Lindsay DA. Multiple exercise and histamine challenge in asthmatic patients. Thorax 1980;35:164-70.

9 Ruffin RE, Alpers JH, Crockett AJ, Hamilton R. Repeated histamine inhalation tests in asthmatic patients. $J$ Allergy Clin Immunol 1981;67:285-9.

${ }^{10}$ Itkin IH. Bronchial hypersensitivity to mecholyl and histamine in asthma subjects. J Allergy Clin Immunol 1967;40:245-56.

"Spector SL, Farr RS. A comparison of methacholine and histamine inhalation in asthmatics. $J$ Allergy Clin Immunol 1975;56:308-16.

${ }_{12}$ Wilson N, Vickers H, Taylor G, Silverman M. Objective test for food sensitivity in asthmatic children: increased bronchial reactivity after cola drinks. $\mathrm{Br}$ Med J 1982;284:1226-8.

${ }^{13}$ Godfrey S, Kamburoff PL, Nairn JR. Spirometry, lung volumes and airway resistance in normal children aged 5-18 years. Br J Dis Chest 1970;64:15-24. 